\title{
Satellite-Based Precipitation Estimation for Hydropower Development
}

\author{
Bijaya Tamrakar and Knut Alfredsen
}

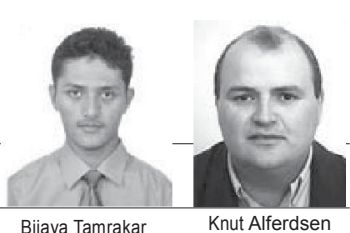

Abstract: Runoff is one of the major factors that govern the capacity of a hydropower project. Precipitation data are needed for estimation of runoff through runoff simulation using a hydrological model. Dense setup of rain gauge network in a mountainous topography is difficult and expensive. An alternative for this problem is the use of Satellite precipitation data with high spatial and temporal resolution. They have an additional advantage that they represent areal precipitation. But, these data should be duly evaluated before using them. In this study, Tropical Rainfall Measuring Mission (TRMM 3B42) precipitation data are evaluated using ground based precipitation stations over Nepal and fed in a rainfall-runoff model to estimate monthly discharge through four of the major basins of Nepal. A simple water balance model has been used, initially developed by Thornthwaite. Statistical parameters showed significant under-estimation of precipitation over major areas of Nepal. The results from the water balance model presented quiet a good estimation of discharge through basins with an average Nash Sutcliffe Efficiency $\left(R^{2}\right)$ value of 0.8 . This implies that TRMM data can be used for runoff simulations over Nepal. The TRMM satellite data can be used during the planning stage of hydropower projects as well as on ungauged catchments.

Key words: TRMM, satellite precipitation, rainfall-runoff model, Thornthwaite water balance, Nepal

\section{Introduction}

D ischarge and head are the major factors that govern the capacity of the hydropower plant. Head is dependent on topography and discharge depends on catchment characteristics and precipitation falling over the area. Discharge simulation over an area requires measurement of precipitation and feeding data in a hydrological model. The study of spatial and temporal distribution of rainfall is the first step for the planning and development of water resources of the catchment (Islam 2009). A conventional way of measurement of precipitation is done by point measurement from ground based station which is converted to an areal precipitation using different approaches. This needs adequate number of stations spread over the catchment to understand the spatial and temporal variations of precipitation.

Regarding the study of precipitation in case of Nepal, there is a huge change in precipitation pattern even in a small region due to highly undulating surface topography with high hills, mountains and valleys. Moreover, it is rather difficult and expensive to arrange a dense setup of rain gauge network and their periodical maintenance for the study of the spatial variation of precipitation (Islam 2009). In Nepal, though the elevation ranges from $60 \mathrm{~m}$ to $8,848 \mathrm{~m}$, there are only 9 rain gauge stations above 3,300 masl and no gauge stations above 3,900 masl. Most of the river basins remain ungauged. Taking an example, the Lapche Hydropower Project has been identified with a gross head of 1, ooom and intake at an elevation of $3,000 m$. There had been difficulty in understanding the hydrology of the catchment of this project since there were no any recorded data in the catchment of this project. No rain gauge stations have been installed in this elevation range. This could probably be due to difficulty in setup and periodic maintenance of the gauge station as it needs three days of walk from serviceable road to reach the project area.

So, an alternative method for estimating precipitation and thus the discharge through the catchment is required. During the last decade, satellite sensing technologies have been introduced for the estimation of global precipitation. Satellite precipitation maps are derived from satellite observations of infrared, passive microwave and space borne precipitation radar. They also have an advantage over the conventional method as they provide areal estimation instead of point measurement.

In recent years, a number of precipitation products have been developed. The present study undertakes the evaluation and validation of TRMM satellite product relative to precipitation measured in gauges over major basins of Nepal and investigates their application for the determination of monthly water balance over major basins of Nepal, which is presented in Figure 1. The detailed study of TRMM precipitation has been restricted only to the Trishuli catchment (Barros 2000), Narayani Basin (Ghaju 2010) and Bagmati Basin (Shrestha 2008) of the country. 


\section{Data Source and Methodology}

TRMM Satellite Data

TRMM is a joint mission between National Aeronautics and Space Administration (NASA) of USA and National Space Development Agency (NASDA) (now merged into Japan Aerospace Exploring Agency (JAEA)) of Japan. The satellite estimates rainfall and energy exchange on tropical and subtropical regions of the world based on the characteristics of cloud

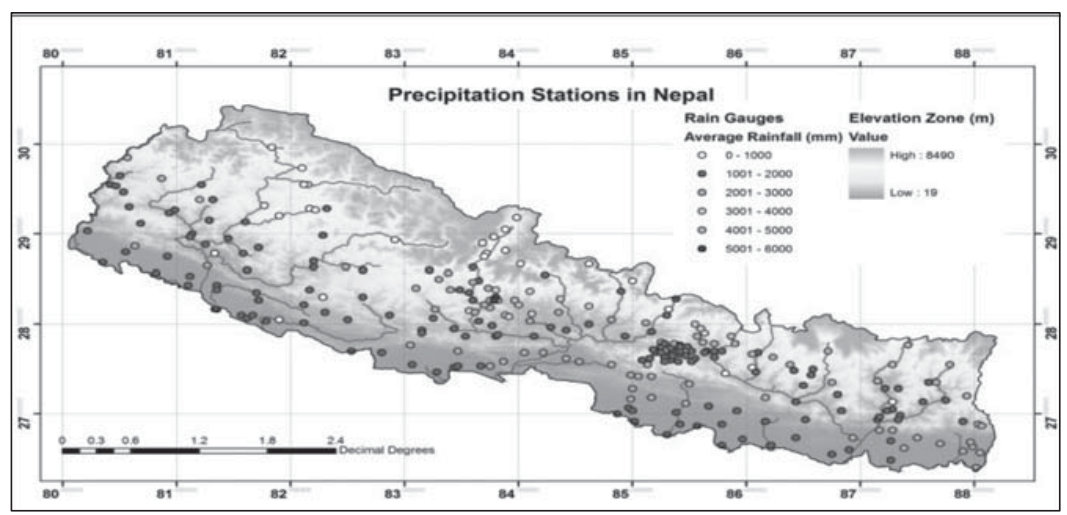
tops, cloud cover and temperature. TRMM satellite data Figure 2. Precipitation Stations over Nepal. are available with different levels of calibration and resolution. Among them, TRMM 3B42 version 6 has been used for the study as this product has high temporal resolution and is calibrated and produced after different levels of processing. The principal characteristics of this product are presented in Table 1.

\begin{tabular}{|l|l|}
\hline \multicolumn{1}{|c|}{ Description } & \\
\hline Data Extent & 1998 to present \\
\hline Geographic Coverage & $\begin{array}{l}\text { Latitude: } 50^{\circ} \mathrm{S} \text { to } 50^{\circ} \mathrm{N} \\
\text { Longitude: } 180^{\circ} \mathrm{W} \text { to } 180^{\circ} \mathrm{E}\end{array}$ \\
\hline Temporal Resolution & $3-$ Hours \\
\hline Spatial Resolution & $0.25^{\circ} \times 0.25^{\circ}$ \\
\hline Grid Size & $400 \times 1440$ pixels \\
\hline Average File Size & $\begin{array}{l}\text { Compressed: } \sim 285 \mathrm{~KB} ; \\
\text { Original: } \sim 4.5 \mathrm{MB}\end{array}$ \\
\hline Projection & Geographic WGS 1984 \\
\hline Data Format & HDF \\
\hline Precipitation measurement & $\mathrm{mm} / \mathrm{hr}$. \\
\hline Missing value & -999.9 \\
\hline \multicolumn{2}{|l|}{ Table 1. Characteristics of TRMM Satellite Data. } \\
\hline
\end{tabular}

\section{Rain Gauge Data}

Rain gauge data are needed for statistical comparison of satellite data for evaluation. Daily rainfall data are collected from 2001 to 2008 for 272 gauge stations spread all over the country. The data are collected from the Department of Hydrology and Meteorology (DHM), Ministry of Environment, Science and Technology, Government of Nepal. The data quality was also checked for individual stations.

\section{Methodology}

The raw TRMM data are in HDF format. These data need to undertake a series of processing steps before they could be used to compare with measurements from rain gauges. The steps include format conversion, rotation, clipping, filling of missing data and temporal aggregation. The aggregation is done from 3:00 UTC to 03:00 UTC of the next day. Since large numbers of three hourly TRMM maps are involved, it seems impractical to carry out data processing manually. So, a series of scripts are prepared in Python programming language to automate the processing of TRMM precipitation data. The scripts were initially developed at NTNU (Abdella

and Alfredsen 2010; Ghaju 2010) and modified during this study.

The first step includes the conversion of HDF5 files to ASCII grid using external translator library as HDF5 format is not supported by ArcGIS. ASCII grids are rotated counter clockwise to get them in exact grid. These grids are clipped to an area of study to ease handling of data file. The 3-hourly precipitation data are then accumulated as daily, monthly and yearly precipitation maps. The pixel values are then extracted at the gauge locations from these precipitation maps based on gauge coordinates and elevation. Quantitative precipitation estimates from the TRMM satellite data are compared with the available gauge precipitation measurements using different statistical parameters like scatter plot, Nash-Sutcliffe coefficient of efficiency $\left(\mathrm{R}^{2}\right)$, coefficient of correlation (RR), Normalized Accumulated Difference (NAD), Root Mean Square Difference (RMSD), Mean Absolute Difference (MAD), Mean Relative Absolute Difference (MRAD), Estimation Bias (EB), Satellite Conditional Probability of Detection (CPOD_S), Gauge Conditional Probability of Detection (CPOD_D).

The Nash-Sutcliffe coefficient is given as (Nash and Sutcliffe 1970):

$$
R^{2}=1-\frac{\sum_{1}^{N}\left(S P_{i}-G P_{i}\right)^{2}}{\sum_{1}^{N}\left(G P_{i}-\operatorname{Avg} \cdot G P\right)^{2}}
$$

The range of the index is 1 (perfect fit) to negative infinity.

Estimation Bias (EB) is the normalized difference between the satellite and gauge precipitation data sets evaluated over a long period of time. It is calculated in percentage and is defined as:

$$
E B=\frac{\sum_{1}^{N} S P_{i}-\sum_{1}^{N} G P_{i}}{\sum_{1}^{N} G P_{i}} \times 100
$$

Satellite conditional probability of detection (CPOD_S) is the measure of probability that precipitation recorded by a gauge is detected by the satellite (Wang 2008). The following equation is used to compute this probability: 
$C P O D_{-} S=\frac{\text { No.of days when }(G P>0.1 \text { and } S P>0)}{\text { No.of days when }(G P>0.1 \text { and } S P \geq 0)}$

Similarly, Gauge conditional probability of detection (CPOD_G) is the measure of probability that precipitation recorded in a satellite is recorded in a gauge (Wang 2008). The following equation is used to find this probability:

$C P O D_{-} G=\frac{\text { No.of days when }(S P>0.1 \text { and } G P>0)}{\text { No.of days when }(S P>0.1 \text { and } G P \geq 0)}$

Where, GP represents gauge precipitation and SP represents the satellite precipitation.

\section{Results of Comparison}

For comparison, gauge stations with lots of missing data are rejected from analysis; the rejection criteria being ratio of gauge precipitation days and satellite precipitation days are less than o.8. Additionally, precipitation days with zero recordings on both gauge and satellite are also excluded.

\section{Point to Pixel Comparison}

The point measurement of gauge station is compared with the pixel value of satellite derived precipitation at same location. The degree of accuracy depends on pixel resolution. Pixel to pixel method of comparison is not adopted since precipitation stations are not uniformly distributed over Nepal. If stations are scattered and the distance between points are more, there is less influence on the output value of the cell. Nepal has very few precipitation stations at higher elevations. So, this method would provide the precipitation value for a pixel with high error. The accumulated daily, monthly and yearly precipitation TRMM maps are evaluated using Gauge Precipitation data from 2001 to 2008. The results of comparison are summarized in Table 2.

The results show that the TRMM satellite data is deviated from the observed precipitation over most of the gauge stations as the $\mathrm{R}^{2}$ value is low and negative in most cases. Also, there is a significant $(\mathrm{p}<0.01)$ decreasing Manangbhot (St 820)) recorded very low precipitations

\begin{tabular}{|l|c|c|c|c|c|c|}
\hline \multirow{2}{*}{$\begin{array}{c}\text { Statistical } \\
\text { Parameters }\end{array}$} & \multicolumn{2}{|c|}{ Daily } & \multicolumn{2}{c|}{ Monthly } & \multicolumn{2}{c|}{ Yearly } \\
\cline { 2 - 7 } & Max & Min & Max & Min & Max & Min \\
\hline R $^{2}$ & 0.18 & -5.42 & 0.88 & -19.47 & 0.48 & -51.82 \\
\hline RR & 0.60 & -0.06 & 0.95 & 0.81 & 0.80 & -0.86 \\
\hline RMSD & 56.54 & 8.05 & 519.41 & 42.90 & 3914.97 & 167.99 \\
\hline MAD & 32.83 & 4.85 & 346.67 & 29.94 & 3851.18 & 145.29 \\
\hline NAD & 53.23 & -75.95 & 164.08 & -78.68 & 359.67 & -78.90 \\
\hline MRAD & 11.61 & 0.74 & 7.98 & 0.38 & 6.15 & 0.15 \\
\hline CPOD_S & 0.89 & 0.47 & 1.00 & 0.91 & 1.00 & 1.00 \\
\hline CPOD_G & 0.89 & 0.14 & 0.99 & 0.55 & 1.00 & 0.83 \\
\hline EB & 332.03 & -78.44 & 233.44 & -78.65 & 359.67 & -78.90 \\
\hline
\end{tabular}

Table 2. Comparison Results.

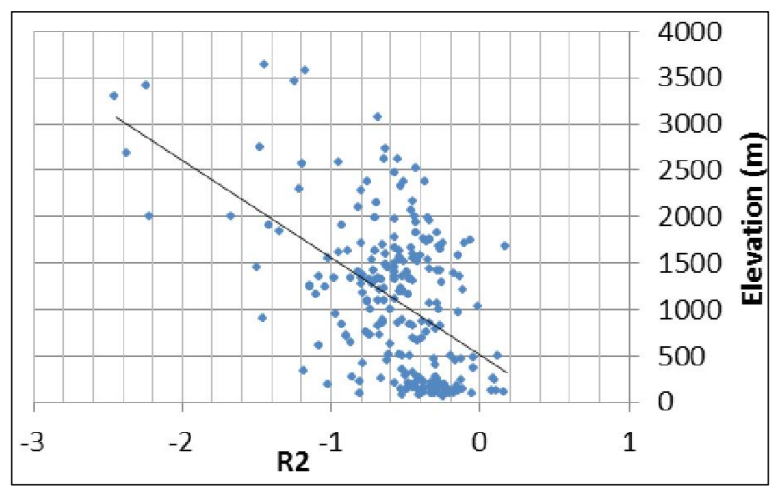

Figure 3. Nash-Sutcliffe, $\mathrm{R}^{2}$ vs. Elevation for Daily Data

trend of $\mathrm{R}^{2}$ with elevation that depicts less accuracy with increase in elevation as shown in Figure 3. An average of $-10 \%$ of Estimation Bias shows an underestimation. An overall average of CPOD_S of 0.7 reflects good detection of precipitation by TRMM.

Monthly accumulated TRMM data represent better estimation of precipitation as $\mathrm{R}^{2}$ values for most of the gauge stations lie between 0.5 to 1 . This could have resulted due to accumulation of positive and negative errors in the estimation of precipitation by TRMM satellite data. The spatial variability of $\mathrm{R}^{2}$ over gauge locations is presented in Figure 4.

During comparison, it is observed that some gauge stations (Samargaon (St 624), Sanda (St 625), Comparison.

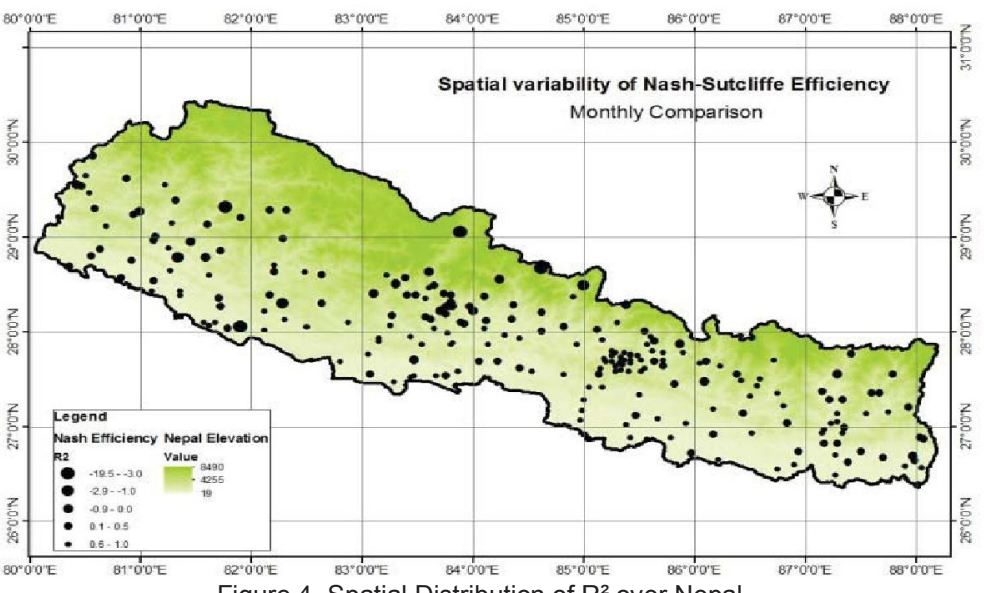

Figure 4. Spatial Distribution of $\mathrm{R}^{2}$ over Nepal.
Manangbhot (St 820)) recorded very low precipitations stations are in a rain shadow zone. As these stations lie in a very remote areaand unskilled local person are employed, there could be error due to lack of proper maintenance, precipitation loss or false reading. The scattered plot for Samargaon (St 624) for the average monthly precipitation is shown in Figure 5. This underlines that there could also be potential errors in gauge data, and it is also worth mentioning that no correction is applied for catch deficiency in any of the data. 


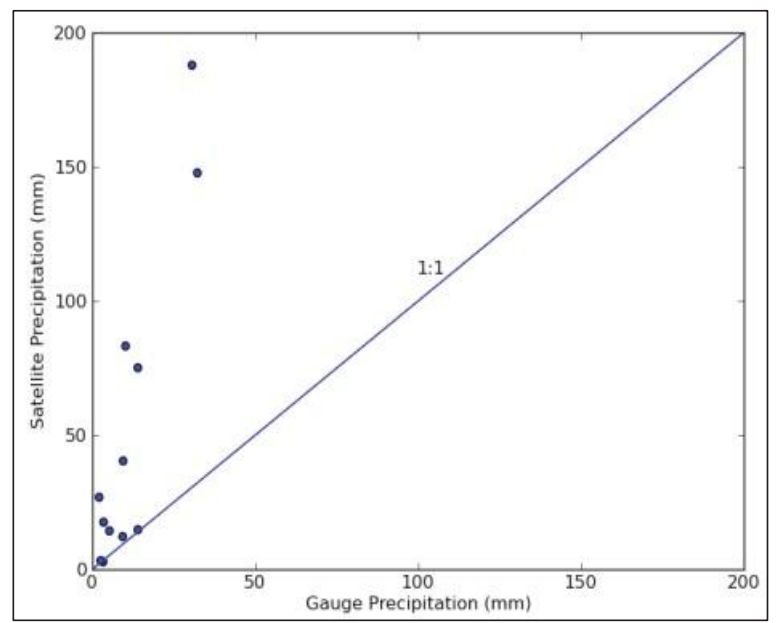

Figure 5. Scatter Plot for Monthly Average Precipitation (Samargaon, St 624)

\section{Spatial Variability within a Single Pixel}

The pixel resolution of TRMM $3 \mathrm{~B} 42$ map is $0.25^{\circ} \times 0.25^{\circ}$ which is nearly equal to an area of $27.5 \mathrm{~km} \times 27.5 \mathrm{~km}$. So, the precipitation for this area will share a single value. A comparison is also made between a single pixel and gauge station lying within same pixel. A pixel between $85^{\circ} 15^{\prime} \mathrm{E}$ to $85^{\circ} 30^{\prime} \mathrm{E}$ and $27^{\circ} 30^{\prime} \mathrm{N}$ to $27^{\circ} 45^{\prime} \mathrm{N}$ is considered in which 11 stations lie within same pixel.

Table 3 depicts that there is a high spatial variability even within a small area.

The correlation between rainfall stations is very low despite of the elevation difference. The comparison between TRMM pixel value and gauge station are made from 2001 to 2008 for daily, monthly, yearly and average monthly precipitations.

\begin{tabular}{|c|c|c|c|}
\hline $\begin{array}{c}\text { S. } \\
\text { No }\end{array}$ & Station Pair & $\begin{array}{l}\text { Elevation } \\
\text { diff. (m) }\end{array}$ & RR \\
\hline 1 & 1030 vs. 1039 & 2 & 0.27 \\
\hline 2 & 1052 vs. 1080 & 11 & 0.23 \\
\hline 3 & 1029 vs. 1030 & 13 & 0.26 \\
\hline 4 & 1029 vs. 1039 & 15 & 0.19 \\
\hline 5 & 1022 vs. 1029 & 50 & 0.38 \\
\hline 6 & 1052 vs. 1082 & 98 & 0.44 \\
\hline 7 & 1060 vs. 1075 & 142 & 0.18 \\
\hline 8 & 1073 vs. 1082 & 216 & 0.35 \\
\hline 9 & 1060 vs. 1073 & 236 & 0.22 \\
\hline
\end{tabular}

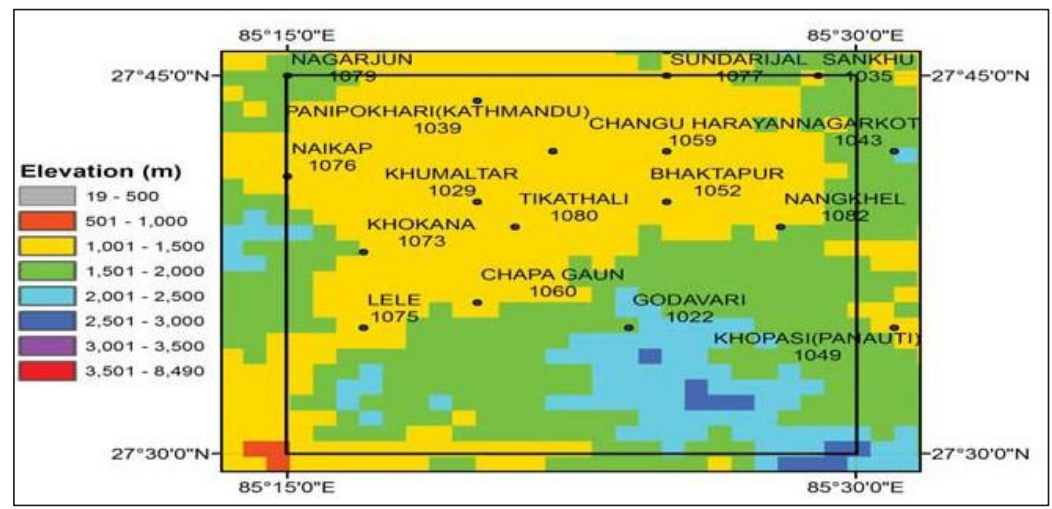

Table 3. Variation of RR within same Pixel for Daily Precipitation Data.

A comparative graph of the annual and mean monthly precipitation recorded by gauge station and TRMM for the pixel is presented in Figure 6. It can be seen from the comparison that the annual precipitation recorded in the gauge stations in 2004 varies from 1100 to $1800 \mathrm{~mm}$ even within a single pixel whereas TRMM refers to a value of $1600 \mathrm{~mm}$. This states that TRMM is estimating an average value for the pixel. Similar findings can be derived from the mean monthly precipitation comparison as shown in Figure 6. This states that the error in TRMM data might have resulted due to averaging of the precipitation value for the pixel.
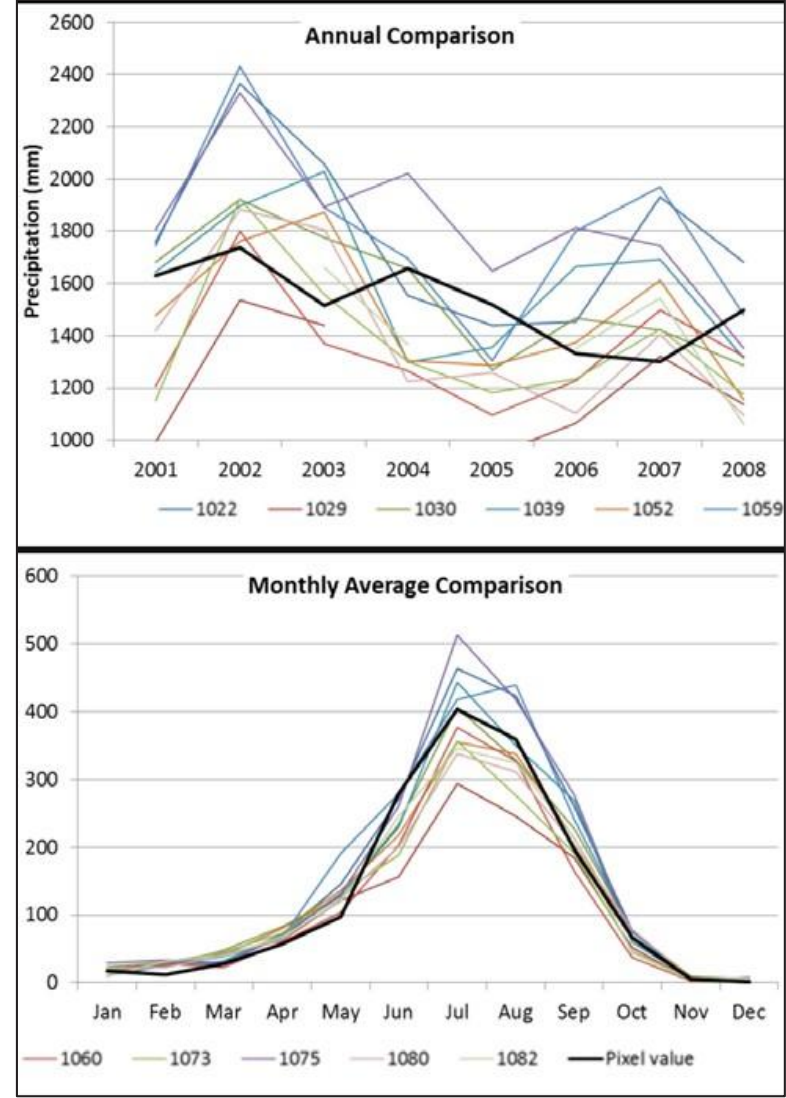

Figure 6. Variation of Precipitation within the Same Pixel.

\section{Monthly Water Balance Model}

One of the applications of the precipitation study is for its use as an input for rainfall-runoff modeling. The model predicts surface runoff from the catchment. A monthly Water Balance model has been widely employed for long term forecasting of water resources distribution. Though a wide range of complicated water balance models with many catchment parameters have been developed, a simple monthly water balance model can still be efficient and useful in terms of runoff simulation.

The model used for the study was initially developed by Thornthwaite (Thornthwaite, 1948). The study used 


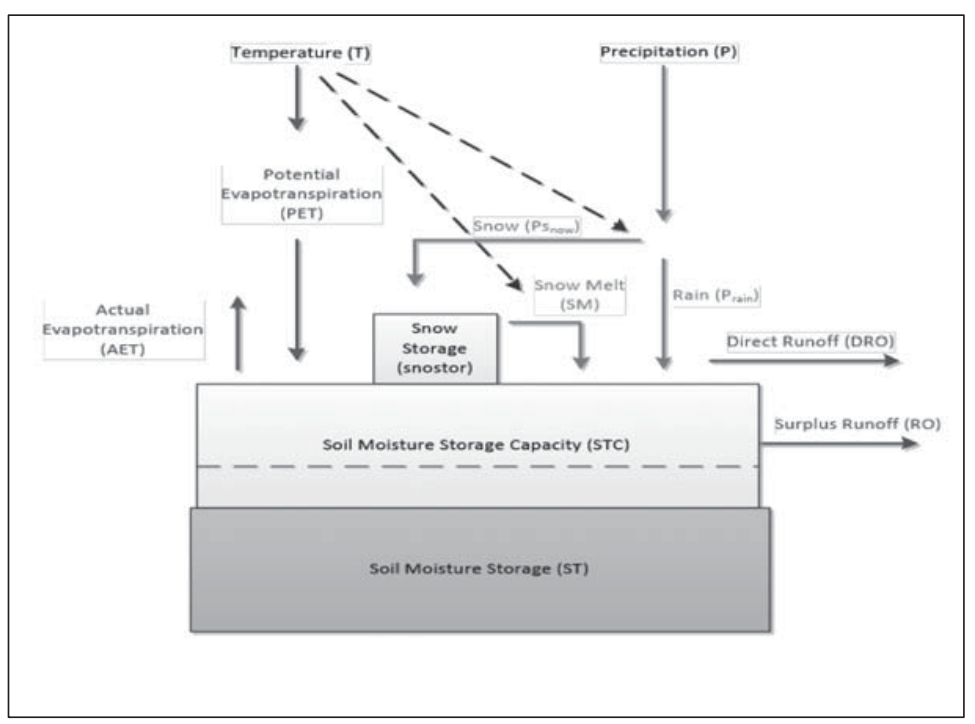

Figure 7. Thornthwaite Monthly Water Balance Model.

threshold for rain $\left(\mathrm{T}_{\text {Snow }}\right)$, all precipitation is considered as rain. If the temperature is in between $\mathrm{T}_{\text {Snow }}$ and $\mathrm{T}_{\text {rain }}$, the amount of accumulated snow and rain varies inearly with temperature. The threshold temperature for rain $\left(\mathrm{T}_{\text {rain }}\right)$ is taken as $3.3^{\circ} \mathrm{C}$ and that for snow $\left(\mathrm{T}_{\text {Snow }}\right)$ depends on elevation which is equal to $-10^{\circ} \mathrm{C}$ for elevation below $1,000 \mathrm{~m}$ and $-1{ }^{\circ} \mathrm{C}$ for above $1,000 \mathrm{~m}$. The amount of snow that melts from the accumulated snow depends on the mean monthly temperature and maximum melt rate.

For this model, the monthly Potential Evapotranspiration (PET) is estimated using Hamon's equation (Hamon, 1961). Hamon's equation assumes that there is abundant water in the catchment. Actual evapotranspiration is then derived from this PET, total precipitation (PTotal), soil moisture storage (ST) and soil moisture storage

the 3 parameter monthly water balance model for 4 major basins of Nepal. The scripts were prepared in $\mathrm{R}$ software by Emmannuel Jjunju (NTNU, PhD) to handle the distributed simulation.

The model consist of two storage parameters: soil moisture capacity and storage constant. The model assumes that some fraction of the precipitation is immediately transformed to direct runoff. Inputs to the model are mean monthly temperature and total monthly precipitation. The potential Evapo-transpiration is calculated with respect to the latitude of the location. The framework of the model structure is presented in Figure 7.

The form of precipitation over the catchment (either snow, rain or both) is determined by the threshold temperature for rain and snow. If the temperature is below the threshold temperature for snow $\left(\mathrm{T}_{\text {Snow }}\right)$, all precipitation will be snow. When the temperature is greater than the withdrawal (STW). When PTotal exceeds PET, the excess water replenishes soil moisture storage and when ST becomes greater than STC, surplus water flows as runoff. Soil moisture storage withdrawal decreases linearly with decreasing Soil moisture storage (ST). The total runoff from the catchment is then calculated as the sum of direct runoff and surplus runoff.

\section{Data Preparation}

The model has been simulated over 4 major basins of Nepal namely Karnali, Narayani, Bagmati and Saptakoshi. The hydro $1 \mathrm{k}$ DEM model of the basins is presented in Figure 1.

The elevation of the basins range from $60 \mathrm{~m}$ to $8,848 \mathrm{~m}$, the higher elevations being in the northern part and low lands on the southern part. Thus, snow/ice has a major contribution on the discharge through the
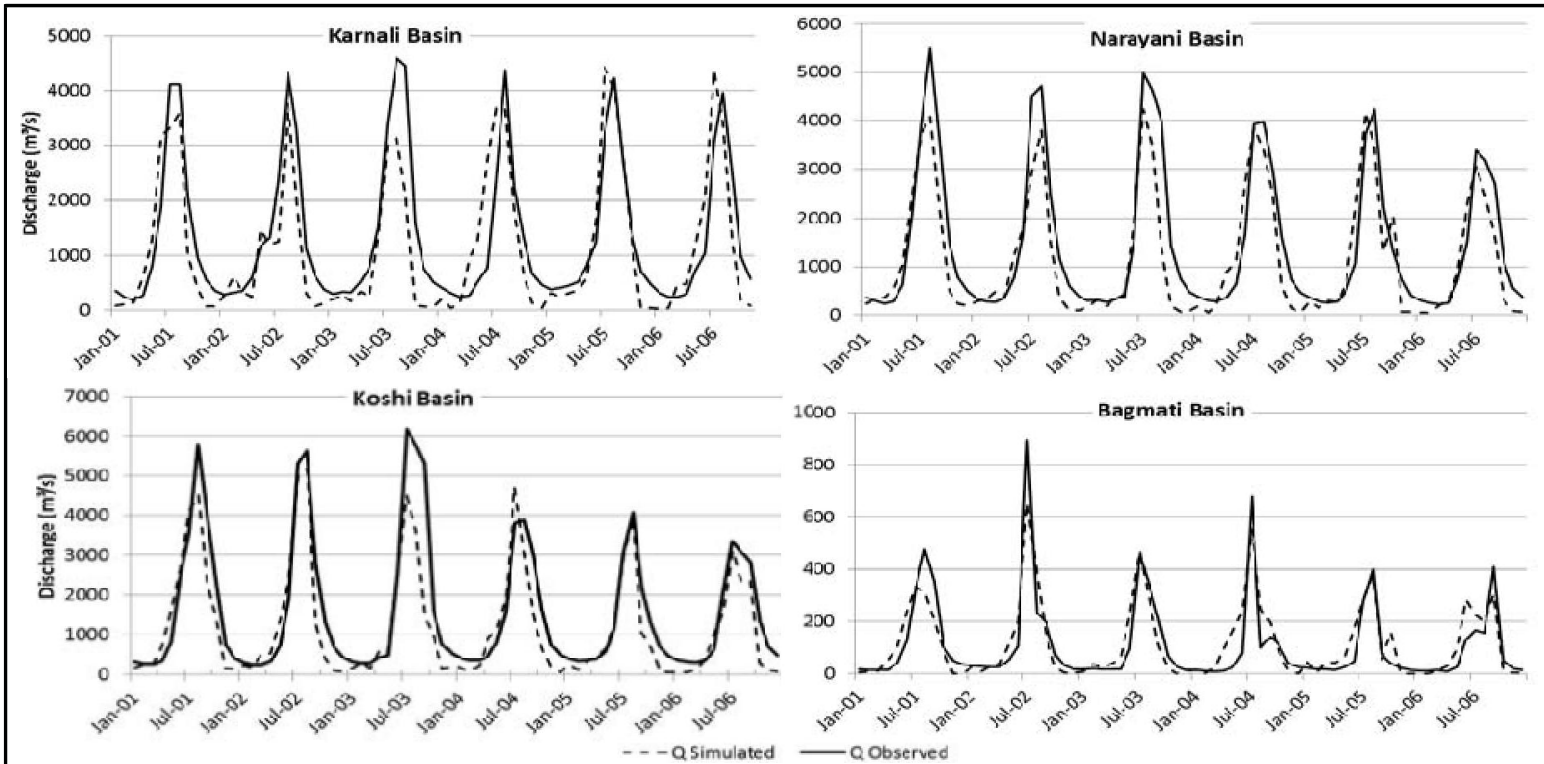

Figure 8. Simulated and Gauge Discharge for Major Basin. 


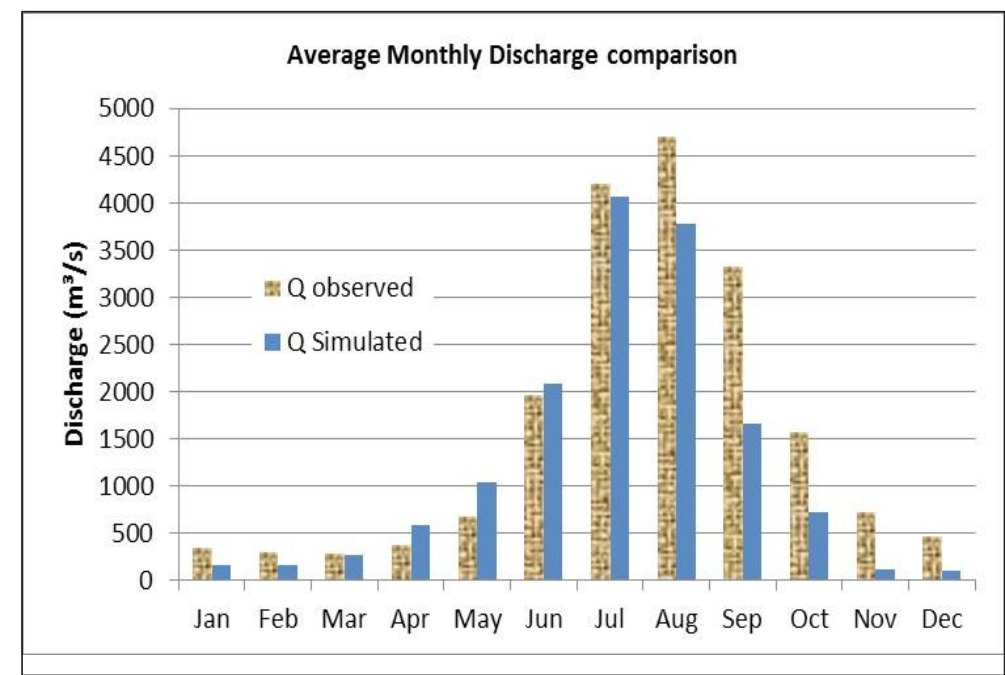

for the Narayani basin is presented in Figure 10. The $\mathrm{R}^{2}$ values obtained for the Karnali, Narayani, Bagmati, Saptakoshi and Sunkoshi basins are respectively $0.745,0.826,0.803,0.816$ and 0.802 . This shows quite a good estimation of discharge for big basins using a simple rainfall-runoff model.

An average runoff map is created using the monthly discharge computed by the model for each cell. The pixel size is $0.25^{\circ} \times 0.25^{\circ}$. The map can be used for initial planning of water resource projects like hydropower project to estimate the discharge through a point, e.g. as a tool in scaling the observed discharge to study sites.

Figure 9. Mean Monthly Discharge for Saptakoshi Basin.

basin. Temperature data from each basin were collected to prepare a monthly temperature map with an adiabatic lapse rate of $-0.005^{\circ} \mathrm{C} / \mathrm{m}$. TRMM satellite maps were used to feed monthly precipitation data for the model. Since the spatial resolution of TRMM data is $0.25^{\circ} \mathrm{x}$ $0.25^{\circ}$, temperature maps were also prepared of the same resolution.

River discharge data is used for the calibration of parameters for the model and comparison. The data are collected from the DHM.

\section{Simulation and Results}

The Thornthwaite water balance model was calibrated for 4 major basins of Nepal using TRMM precipitation data. The parameters have been adjusted for the best fit of the simulated discharge curve. The parameters possess similar values for all of the basins. High direct runoff factor indicates that $90 \%$ of the rainfall is drained immediately by rivers resulting in flash floods.

The mean monthly observed and simulated discharges were plotted from 2001 to 2006 for each basin as shown in Figure 8. The figure shows quite a good match between the observed and simulated values except for the fact that the model is not able to represent the falling limb in some years, but this should not influence

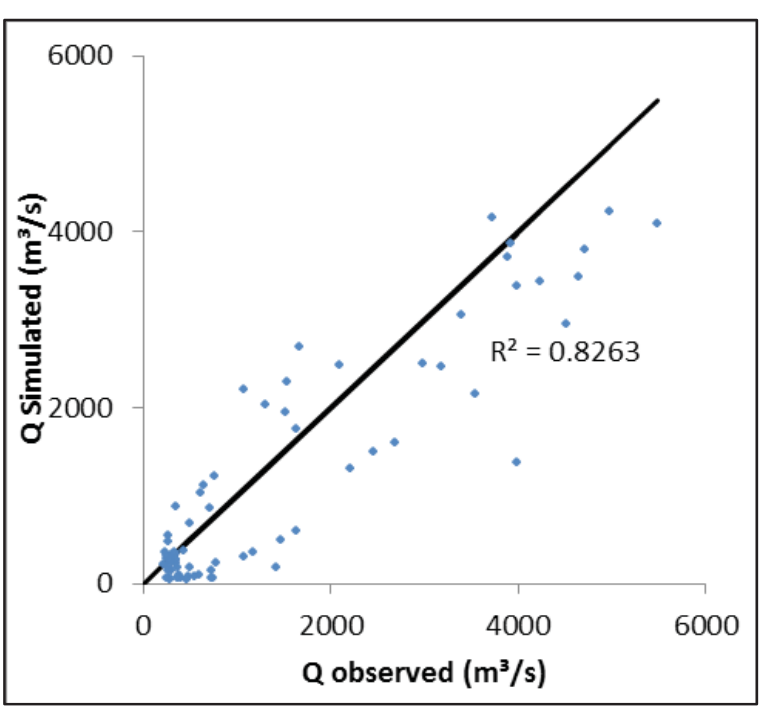

Figure 10. Scatter Plot for Narayani Basin with Coefficient of Correlation.

\section{Conclusion}

The study results showed a clear indication of the underestimation of precipitation by TRMM satellite data. The conclusions derived from this work seem to be in good agreement with the results from Barros the computation of annual runoff value used in the runoff map.

The average observed simulated discharges for each month are also compared. The comparison shows that the model has a good estimation of the rising limb, but the recession limb is not yet estimated perfectly. The graph for the Saptakoshi basin is presented in Figure 9.

A scattered plot is also prepared to observe the variation in the gauge and simulated discharge. The plot

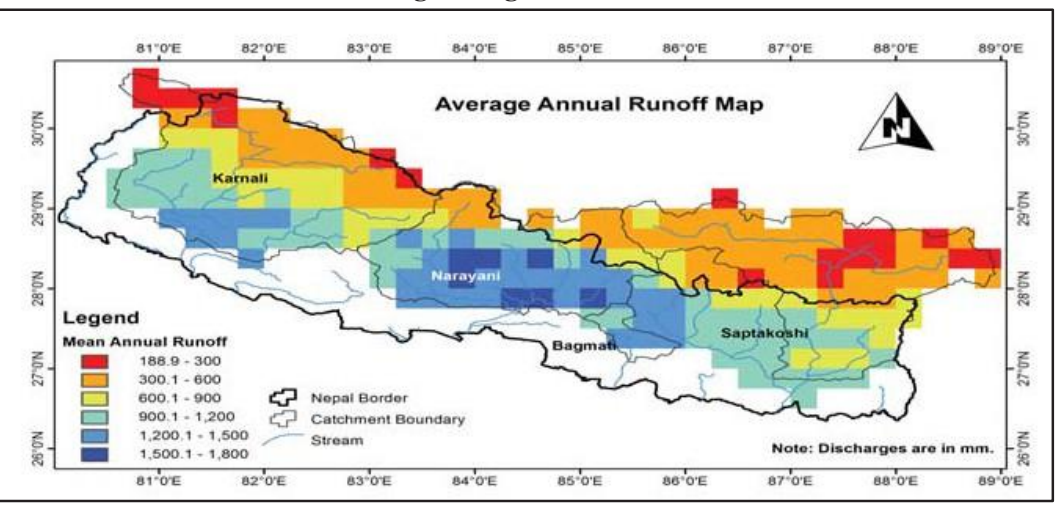

Figure 11. Average Runoff Map of Nepal. 
(2000), Shrestha (2008) and Ghaju (2010). Yet, the results also suggest that TRMM could be applied for runoff simulation to the catchments where there is no precipitation station for early investigations.

The study used a very simple rainfall-runoff model for runoff simulation. A better model can be employed to observe the detailed characteristics of TRMM data. An extensive study and research should be done for investigation on the use of TRMM data over the country before making a concrete conclusion.

\section{Acknowledgements}

The authors would like to thank Yisak Abdella, Sintef and Emmanuel Jjunju, PhD, NTNU for their meaningful support during the study.

Bijaya Tamrakar, MSc, Hydropower Development, is a graduate in Civil Engineering at Tribhuwan University (2008) and has obtained Master's degree at Norwegian University of Science and Technology (NTNU, 2011). He is currently working with Solu Hydroelectric Project (23.5 MW), Nepal.

Corresponding address: vj_tams@hotmail.com

Knut Alfredsen is a Professor at the Department of Hydraulic and Environmental Engineering, Norwegian University of Science and Technology. Has has been working at the department since 2002. Professor Alfredsen holds a PhD in Hydraulic Engineering from NTNU. His areas of research are hydrological modelling, cold climate hydrology and environmental impacts of hydropower. He has published 30 papers in international peer-reviewed journals.

Corresponding address: knut.alfredsen@ntnu.no

\section{References}

Abdella, Y.S. and K. Alfredsen, 2010, "A GIS toolset for automated processing and analysis of radar precipitation data". Computers and Geosciences $201036(4): 422-429$.

Barros, A. P., 2000, "A study of the 1999 monsoon rainfall in a mountainous region in central Nepal using TRMM products and rain gauge observations." Geophysical research letters 27(22): 3683 .

Ghaju, S., 2010, Evaluation of Satellite based precipitation for Hydrological modelling in Narayani basin in Nepal. Master Thesis, NTNU.

Hamon, W.R., 1961, Estimating Potential Evapotranspiration. Journal of the Hydraulics Division, Proceedings of the American Society of Civil Engineers, 1961. 87:p 13.

Hughes, D. A., 2006, Comparison of satellite rainfall data with observations from gauging station networks. Journal of Hydrology, 2006. 327(3-4): p. 399-410.

Islam, D. M. N., 2009, Analysis of TRMM data in Monitoring Rainfall over Mountainous Regions, SAARC Meteorological Research centre (SMRC). SMRC Report No. 27.

Nash, J. E. ands J. V. Sutcliffe, 1970, River flow forecasting through conceptual models part I-A discussion of principles, Journal of Hydrology, Volume 10, Issue 3, April 1970, Pages 282-290.

Shrestha, M. S., et al. 2008, Using satellite-based rainfall estimates for streamflow modelling: Bagmati Basin. Journal of Flood Risk Management, 2008. 1(2): p. 89-99.

Thornthwaite, C.W., 1948, An Approach toward a Rational Classification of Climate. Geographical Review, 1948. 38(1): p. 55-94.

Wang, X., et al., 2008, Validating NEXRAD MPE and Stage III precipitation products for uniform rainfall on the Upper Guadalupe River Basin of the Texas Hill Country. Journal of Hydrology, 2008. 348(1-2): p. 73-86.

\section{CALENDAR OF EVENTS - HYDROPOWER AND DAMS}

5-6 March, 2013: HydroVision Russia. Location: Moscow, Russia. More info: http://www. hydrovision-russia.com/en_GB/index.html

16-18 April, 2013: Water Storage and Hydropower Development for Africa. Location: Addis Ababa, Ethopia. Contact Email: mb@hydropower-dams. com. More info: http://www.hydropower-dams. com.

22-24 April, 2013: National Hydropower Association Annual Conference. Location: Capital Hilton, Washington D.C., USA. More info: http://www. nationalhydroconference.com/index.html

6-8 May, 2013: HydroVision India 2013. Location: Bombay Exhibition Centre. Location: Goregaon, Mumbai, India . More info: http://www. hydrovisionindia.com/index.html

21-24 May, 2013: IHA World Congress on Advancing Sustainable Hydropower. Location: Kuching, Malaysia. More info: http://www.ich.no/
4-6 June, 2013: POWER-GEN Europe Conference and Exhibition. Location: Vienna, Austria. More info: http://www.powergeneurope.com/index.html

23 - 26 July, 2013: HydroVision International 2013. Location: Colorado Convention Center Denver, Colorado, USA. More info: http://www. hydroevent.com/index.html

9-11 September, 2013: 4th Australasian Hydropower Conference 2013, Synergies with other renewableswind and irrigation. Location: Rotorua, New Zealand. More info: http://www.hydroconference. co.nz/

24-26 September, 2013: HydroVision Brasil. Location: Transamerica Expo Center, Sao Paulo, Brasil. More info: http://www.hydrovisionbrasil. com/en/index.html

24-26 September, 2013: Power-gen Brasil. Location: Transamerica Expo Center, Sao Paulo, Brasil. More info: http://www.powergenbrasil.com/en/index.html 